\title{
A New Way of Using the Interactive Whiteboard in a High School Physics Classroom: A Case Study
}

\author{
Bor Gregorcic $^{1}$ (D) Eugenia Etkina $^{2} \cdot$ Gorazd Planinsic $^{3}$
}

C The Author(s) 2017. This article is published with open access at Springerlink.com

\begin{abstract}
In recent decades, the interactive whiteboard (IWB) has become a relatively common educational tool in Western schools. The IWB is essentially a large touch screen, that enables the user to interact with digital content in ways that are not possible with an ordinary computer-projector-canvas setup. However, the unique possibilities of IWBs are rarely leveraged to enhance teaching and learning beyond the primary school level. This is particularly noticeable in high school physics. We describe how a high school physics teacher learned to use an IWB in a new way, how she planned and implemented a lesson on the topic of orbital motion of planets, and what tensions arose in the process. We used an ethnographic approach to account for the teacher's and involved students' perspectives throughout the process of teacher preparation, lesson planning, and the implementation of the lesson. To interpret the data, we used the conceptual framework of activity theory. We found that an entrenched culture of traditional white/blackboard use in physics instruction interferes with more technologically innovative and more student-centered instructional approaches that leverage the IWB's unique instructional potential. Furthermore, we found that the teacher's confidence in the mastery of the IWB plays a crucial role in the teacher's willingness to transfer agency within the lesson to the students.
\end{abstract}

Keywords Interactive whiteboard · Physics education · Astronomy $\cdot$ High school $\cdot$ Activity theory · Case study · Orbital motion · Kepler's laws · Narrative · Student engagement · Teacher professional development

Bor Gregorcic

bor.gregorcic@physics.uu.se

1 Uppsala University, Uppsala, Sweden

2 Rutgers University, New Brunswick, NJ, USA

3 University of Ljubljana, Ljubljana, Slovenia 


\section{Introduction}

In the last decade, the interactive whiteboard IWB has become a widespread piece of educational technology. One of the main arguments for the massive uptake of IWBs that we have seen in schools is that they can help improve whole-class teaching by adding to the lessons' visual impact and interactivity (Hennessy and London 2013). However, ironically, as Gray (2010) points out, one of the key reasons for the IWB's successful and rapid uptake by teachers is that it can be placed in a traditional classroom without significantly disrupting teacher-centered classroom practices. In fact, many have cautioned that the IWB can even reinforce traditional teaching styles because it is so well suited for whole-class, teacher-led pedagogy (Cutrim Schmid 2011; Higgins et al. 2007; Kennewell et al. 2007; Kennewell 2006; Sweeney 2013; Warwick and Kershner 2008).

The motivation for the study described in this paper came out of the observation of IWB use in authentic physics lessons in a Slovenian high school. In a pilot study (Gregorcic et al. 2014), we observed how experienced physics teachers used the IWB in their lessons. We found that in spite of having good mastery of the technical aspects of IWB use and using some of its features productively, the transition from ordinary whiteboards to IWBs did not change the teachers' classroom practices in any significant way. We found that one of the reasons was that physics teachers lacked ideas concerning using the IWB in a more advanced way, both technically (they mostly used it as an ordinary board, for writing and drawing) and pedagogically, support student-centered activities in their classes. At the same time, two teachers expressed a sincere interest in learning more about the ways that IWB technology could be used to foster a studentengaging learning environment that would also take advantage of the IWB's unique affordances.

To help the teachers advance their use of the IWB, we introduced them to teaching materials that they could apply in their classrooms. This study follows one of the two teachers, as she learned to use the new materials and implemented them in her teaching. We studied in what ways the teacher and students perceived these materials' potential for teaching and learning in physics and in what way the proposed instructional activities differed from what usually happens in physics lessons.

This paper describes and analyzes:

a) The context where the study took place, in particular, the established practice and culture of IWB use in physics instruction.

b) The process of teacher training and preparation of a lesson, which leverages IWB-specific affordances for student kinesthetic engagement (Gregorcic 2015).

c) The implementation of the lesson in an authentic classroom setting.

d) Teacher and student reflections on the implemented lesson and on the use of the IWB in it.

\section{Review of Existing Literature on Interactive Whiteboards}

IWBs have become relatively commonplace in primary and secondary schools in Western countries. The projections for 2016 were that IWBs will be found in $93 \%$ of classrooms in the UK, $80 \%$ of classrooms in Turkey, around $70 \%$ of all classrooms in Denmark and the Netherlands, and more than $50 \%$ of classrooms in Australia and USA (Hennessy and London 2013). Largescale IWB introduction projects such as the Primary Schools whiteboard Expansion project in 
the UK (Somekh et al. 2007) and the FATIH project in Turkey (ERI 2013) have played major roles in spreading the IWB technology into thousands of classrooms.

Following a large-scale introduction of IWBs into Turkish schools, Somyürek et al. (2009) found that more than half of the teachers in their sample reported that they have not been using IWBs in their lessons, in spite of having access to them. The study found that the main reasons for the underutilization of IWBs are the teachers' self-declared lack of technical skills, lack of pedagogical competency on how to integrate the IWB into their teaching, and a lack of appropriate teaching materials to use with the IWB.

For teachers who are just beginning to use the IWB in their teaching, technical skills are their first concern. However, as is common with any new technology, once teachers get familiar with the rudimentary function of the IWB, other issues come to the foreground (Beach 2012). As teachers become familiar with the basic functions of the IWB, they start looking for ways of incorporating it into their teaching in a way that would benefit the learning process.

The increased presence of IWBs in schools has also increased the need for educational research on the topic. the IWB 's' role in teaching and learning of science is no exception. A recent literature review paper on the use of IWBs in science education (Ormanci et al. 2015) showed that while the number of publications on the use of IWBs in education has increased in the last decade, studies that address content-specific use in teaching and learning of science in particular are scarce. Physics-specific research has been even scarcer. We were only able to find a handful of studies dealing with the use of IWBs in physics instruction (Mellingsæter and Bungum 2015; Stoica et al. 2011; Van Veen 2012; Vercellati and Michelini 2014).

Though findings from research on the implementation and use of IWBs suggest guidelines for the introduction of the technology into schools and teacher training (see Slay et al. 2008, for example), as well as classroom use in different subjects, including science (Blanton 2008; Condie and Munro 2007; Hennessy and London 2013; Kennewell and Morgan 2003; Kershner et al. 2010; Koenraad 2008; Mercer et al. 2010; Moss et al. 2007; Murcia and Sheffield 2010; Murcia 2014; Smith et al. 2005; Sweeney 2013; Winzenried et al. 2010), concrete examples of subject-specific instructional materials, studies of their implementations and concrete suggestions on how to design or implement specific instructional materials in the future are few and far between, particularly in physics.

Researchers suggest that further research should focus on the complex system of social interaction and cognition in classroom activities using the IWB (Bax 2010; Beach 2012; Hennessy et al. 2007; Kershner et al. 2010; Mellingsæter and Bungum 2015). This can be done on different scales, using different methods of inquiry: from micro-ethnographic analysis of small-group collaborative learning sessions, to extended case studies of development and evolution of IWB use with individual teachers, classrooms, or schools. Naturally, if we wish to advance our understanding of the possibilities for productive IWB's use in physics teaching and learning, such studies are also necessary in the domain of physics.

\section{Research Methods}

We used an ethnographic research approach (Creswell 2013) to provide an informative narrative from the participating teachers' and students' perspectives. Specifically, we provided an interpretation of the existing practices and the transformation of IWB use that took place during the implementation of new instructional materials on the topic of orbital motion of 
planets. Our data consisted of field observations, video recordings, and voice-recorded interviews with teachers and students involved in the study. To interpret the data, we used the conceptual framework of activity theory (Engeström 1987), which is particularly apt for formative intervention studies, such as the one described in this paper. Activity theory is discussed later in the paper.

\section{Data Collection and Preparation}

In order to set the stage for the study of the implementation of new lesson materials, it is necessary to give an account of the context in which the study took place. In a pilot study, we observed how physics teachers used the IWB in their lessons (Gregorcic et al. 2014) and conducted semi-structured interviews with two of the teachers (Anna and Paul) to get insiders' perspectives on how the introduction of IWBs that took place about 2 years before our study had affected their teaching practice.

Following the pilot study, the researcher worked together with one of the teachers (Anna) to help her implement new instructional materials that focus on leveraging the affordances of IWBs for active student engagement. The researcher who trained Anna to use new IWB-based materials had taught physics to one of the classes at the same school a year before the study. By taking part in the physics-teacher collective and engaging in regular discussion with the physics teachers at the school, he formed a friendly, collegial relationship with them. This helped establish an atmosphere of trust and collaboration that made possible a sincere exchange of ideas and opinions, and allowed the researcher to gain an "insider" perspective on the processes taking place during the study.

During teacher training, the researcher audio-recorded the discussions that took place during one-on-one training sessions. Two lesson implementations were video-recorded with one camera at the back of the classroom. with the researcher sitting at the back of the classroom and taking notes. Two groups (one from each class) of 3 to 4 students participated in a follow-up interview with the researcher approximately a week after the lesson. The interviews were audio recorded.

We transcribed all the interviews and translated the transcriptions into English. We also transcribed the audio from the video-recordings, translated it, and incorporated it into the video recordings as subtitles, making possible more systematic repeated viewings. We interpreted the data using the conceptual framework of activity theory.

\section{Theoretical Framework: Activity Theory}

Activity theory (AT), also referred to as cultural-historical activity theory, is not a predictive theory in a strict natural science sense of the word, but rather a conceptual framework for describing and making sense of human activity. It originates in the ideas of the Soviet culturalhistorical psychology (Vygotsky 1978), and was originally developed by Alexei Leontiev (Kaptelinin and Nardi 2006; Leontiev 1978) and later developed further by Western scholars, most notably Yrjö Engeström (Cole and Engeström 1993; Engeström 1987).

Deriving strongly from Vygotsky's work, activity theory is particularly apt for use in research, where the investigator interacts and influences the studied situation in so-called formative interventions (Engeström 2011). Our decision to use activity theory is thus strongly associated with our selection of research methods. 
While it is impossible to give a comprehensive account of AT in the spatial limitations of this paper, we here provide a brief overview of AT's main principles that are relevant for the study at hand.

In activity theory, an individual (or a group of individuals) who carries agency is called the subjec. The subject acts in order to reach certain goals, and their actions are aimed towards the socalled object (objective) of the activity. The object is not necessarily a physical entity. For example, the object can be a house that is built, or it could be a theory one develops (Jonassen and Rohrer-Murphy 1999). Very often, the subject makes use of tools to act upon the object. Just like the object, the tools can either be physical (e.g., a hammer) or they can be internal (e.g., mnemonic techniques). AT says that tools, on one hand, shape the way the subject interacts with the object and, on the other hand, have developed as a response to the needs of the subjects. The tools are thus shaped by the experiences of people who have used them in the past and "carry with them" a legacy of possibilities and limitations of their use. This legacy is passed on through the process of teaching and learning about when and how to use particular tools.

One of the central principles of AT is that every activity is embedded in a social context (Kaptelinin and Nardi 2006). While social embeddedness was already a prominent feature of Leontiev's AT, Engeström was the first to expand the schematic structure of activity (subject, tool, and object) by adding to it the element (also referred to as a node) of community and two additional mediators,: rules and division of labor. In a similar way that the tool mediates the relationship between the subject and the object, rules mediate the relationship between the subject and the community, and division of labor mediates the relationship between the community and the object (Fig. 1) (Cole and Engeström 1993; Engeström 1987, 2000; Kaptelinin and Nardi 2006). Formal or informal rules shape how the subject relates to the community and the division of labor determines the roles that the members of the community and the subject take-on in pursuing the shared goal of a given activity. The scheme proposed by Engeström (Fig. 1) takes into account the social embeddedness of activity and provides a lens through which it can be viewed and analyzed on different levels, from individual goaldirected behavior to institutionalized and culturally resistant "ways of doing things." Depending on the particular activity of interest, the nodes (i.e., subject, community, object, tools, rules, and division of labor) can shift and scale accordingly. The combination of nodes in Fig. 1 is often referred to as an activity system.

Another central feature of AT is that it regards activity as a constantly changing dynamic process. In AT, the mechanism that drives change in an activity is the resolution of contradictions/tensions associated with the activity. For example, one may have multiple goals that are in competition with each other (Barab et al. 2002). The resolution of tensions, even if partial or temporary, requires a re-alignment or change in one or more of the activity nodes and

Fig. 1 Engeström's

conceptualization of an activity system (Engeström 1987). It consists of the subject, the object, and the community. The relationships between them are mediated by tools, rules, and the division of labor

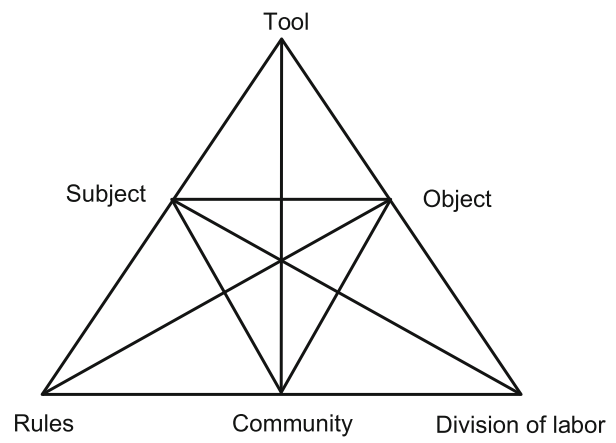


thus causes an activity to change as a whole. Contradictions/tensions can exist on different levels (Barab et al. 2004; Engeström 1987).

Primary contradictions are those within the nodes of the activity (e.g., tensions within the rules or within the division of labor); secondary contradictions are those between the constituent nodes of the activity (e.g., tensions between the subject and the tool), tertiary contradictions arise between the current and an emerging form of an activity (e.g., tensions between a culturally established way and a new way of doing something), and quaternary contradictions arise between the central and bordering activities (e.g., the tension between a student's classroom activities and extra-curricular activities). AT does not see contradictions as nuisances to be eliminated, but rather as the drivers of change. Contradictions or tensions, for example, can be expected to be an essential part of learning activities, since learning essentially means changing the way we think.

\section{Using Activity Theory as an Interpretive Framework in Our Study}

For the purpose of this study, we have chosen to approach the analysis of the activities surrounding the preparation and implementation of a lesson from the perspectives of the participating teachers and students. This means that we will consider two bordering activities - students' engagement in the lesson and teacher's efforts to prepare for and execute the lesson. Our aim is to discern different order contradictions for the two bordering activities, as we have chosen to define them. The desired outcome of the study is to find if and how tensions in the observed students' and teacher's activities can be resolved to help all participants benefit from a new way of using IWBs in physics instruction.

To form a holistic picture from the collected data, we repeatedly read through the teacher and student interview transcripts and video data, and color-coded parts of the text according to the topic that was being discussed: the nodes from the activity scheme in Fig. 1 represent separate color categories. We examined how the tagged snippets of text related to each other across different data sources. Such classification was not intended to function as an objective coding scheme, but rather as a tool to help the researcher, who was already immersed into the situation, to unpack, conceptualize, express in activity theory vocabulary what was going on, and discern relevant features and contradictions in the studied and surrounding activities.

For example, when the topic of conversation was the use of IWB, we tagged it as "tool." When the topic was that of teacher's intentions, it was tagged as "object." A potential tension within the activity system (secondary contradiction, by definition) is that of a teacher (subject) wanting to engage students more actively in their lessons (object), but not having an idea of how to use the IWB (tool) to do that in a way that would match their personal, curricular and students' demands, needs and/or expectations.

In the following section, we give an account of the context of our study and interpret it through the AT lens. Taking the context into account is crucial, since AT considers any activity to be fundamentally shaped by its context.

\section{Context of Our Study}

In this section, we attend to the context of the study by describing the setting in which the study took place and by giving an account of the participating teachers and students' past 
experience with the use of IWBs. We describe the process by which one of the teachers learned to use the IWB and how she further improved and advanced her use of the IWB in the classroom in the past. We also give an account of the involved students' perspectives on the existing culture of IWB use.

The school where the study took place is a four-year gymnasium high school, that prepares students for university. At the time of the study, it had approximately 1000 students and 85 teachers and had been fully equipped with IWBs (43 IWBs) for about two years. Students' ages are typically 14 or 15 when they start first year and 18 or 19 when they finish the last of the four years. All students take physics during the first three years. The study was done with 2 secondyear classes during regular physics lessons.

In line with the principles of AT, painting a picture of the established culture of IWB use was necessary if we wanted to identify its inherent tensions and understand the evolution of the the activities observed during the study. For this purpose, we looked at the findings from our pilot study (Gregorcic et al. 2014), data from interviews with two teachers (Anna and Paul, both approximately 50 years of age at the time of the study), as well as interviews with students. ${ }^{1}$

\section{Teachers Involved in the Study}

Two teachers agreed to participate in our study. We describe how one of them underwent the required amount of lesson preparation and training, which was provided by the researcher, and implemented a lesson that uses the IWB in a new way.

The first participating teacher-Anna - was an experienced physics teacher. She declared herself as not being particularly enthusiastic about technology and computer use in teaching, but did not position herself as being particularly critical towards or against the use of new technologies in teaching and learning.

Anna: I have to say I am not enthusiastic when it comes to different technical aids. I use the IWB, I am in touch with it, because it is clear to me that it exists, that it is useful and good, but I am not among the first people who get into this kind of stuff out of pure interest.

She positioned herself as not being among the most nor the least interested teachers at the school, when it comes to advancing the use of IWBs.

Anna: I wouldn't consider myself as the last one to adopt it. I am somehow in the middle, perhaps. I myself progressed in the last few years from using the most basic tools such as writing, drawing, colors, to using the IWB more and more. From preparing stuff in advance, pictures, graphs...

She also said that she believed she could use the IWB in more advanced ways than she did currently. Her response to the researcher's question of why she thought she does not take full advantage of the IWB's possibilities was:

Anna: With me personally, it is that I am not an IWB enthusiast and it is not a joy for me to stay in school in the afternoon for a week and play with the IWB. I learn what I have

\footnotetext{
${ }^{1}$ Interviews with students were conducted after the implementation of the new lessons in their classroom. However, significant portions of the interviews were spent talking about how the IWBs were used in other subjects and particularly in "ordinary" physics lessons.
} 
to know. Of course I am then glad, when I see I've learned something and I see that I can also perform better. But it is not my personal hobby.

Anna agreed to collaborate in the study and expressed interest in learning to use the IWB in new ways because she had heard some information about a previous implementation of materials on the topic of Kepler's laws in another class that had been taught by the researcher (first author of this paper). The study described in this paper is centered on Anna's implementation of a lesson, where the IWB was used in a novel way to help students explore orbital motion of planets through kinesthetic engagement. Anna chose the class in which she wanted to implement the new lesson, based on the content of the lesson and its placement into the yearly curriculum plan. She chose two of her second-year classes (students 16-17 years of age).

The second participating teacher-,Paul,- - is also an experienced physics teacher. He considered himself tech-savvy, but also regarded himself as being very critical towards ICT use in instruction, often contemplating the usefulness and potential of ICT and questioning its value for the teaching and learning of physics. He collaborated with the researcher in the design and implementation of a unit on geometrical optics, which we do not describe in this paper. However, we use his interview data relating to general issues surrounding IWB use to better understand the existing culture of IWB use.

\section{Uptake of IWB Use at the School}

In mid-2000s, many schools in Slovenia decided to bring IWBs to their classrooms. This implementation, however, has not been accompanied by a state-coordinated professional development program aimed at teachers. Teacher development and preparation for the use of IWBs was an issue every school had to deal with on its own. Tech-savvy teachers have often taken up teacher training at their schools and helped others become familiar with the IWBs' basic functions. The situation at our school was similar. Two physics teachers (Paul and Scott) prepared IWB seminars for teachers of all subjects, some of them compulsory and some of them aimed at teachers particularly interested in getting the most out of the IWB. The two of them learned to use the IWB, as Paul explained, mostly on their own, by experimenting and discussing the IWB's possibilities with each other. Obligatory training that the school administration prescribed for teachers was kept to a minimum, as some teachers did not share Paul and Scott's enthusiasm for the new technology.

Teachers at the school have complete autonomy over how they use the IWB in their lessons. However, certain teacher collectives or individual teachers, for example, music and Slovene language teachers as well as some physics teachers, tend to use the IWB in ways that are more advanced than the typical teacher at the school. The exchange of ideas within groups of teachers seems to be an important mechanism for the advancement of IWB use.

Anna has identified the closely collaborative collective of physics teachers who share a common office space as the place she goes to when she wants to use the IWB (or any other piece of technology) in new ways. She relies on the support of the community of fellow physics teachers (in particular Paul and Scott), who coach her one-on-one when she expresses the need.

\section{Advancing IWB Use}

Even though the community of physics teachers has the capacity to use the IWB in ways that differ from ordinary whiteboard use, our pilot study (Gregorcic et al. 2014), as well as interviews with 
teachers and students have revealed that the way the IWB has typically been used in physics lessons did not differ significantly from the use of regular whiteboards (or chalkboards); it has mostly been used as a writing surface for the teacher (with some advanced drawing features, such as the straight-line tool coming in handy, for example, when drawing ray diagrams) and as a projector for displaying multimedia, which is made more accessible through the IWB's native software. When students used the IWB in physics, they mostly used it as a writing tool to solve textbook-style problems. It thus seems that in the few years since the teachers started using the IWBs, there have been no major changes in what physics lessons look like, especially in terms of student engagement.

What could be the reason for such limited use of IWBs potential in physics lessons? One of the reasons appears to be the scarceness of subject-specific materials in high school-level physics that actually take advantage of what differentiates the IWB from an ordinary projector-its touchscreen functionality - and leverage it for student active engagement. Not surprisingly, most physics teachers at the school saw many of the IWB's advanced native software features, presented to them in dedicated seminars given by IWB merchants, as not having significant potential to contribute to the learning of physics at the high school level. As Anna expressed in one of the interviews:

Anna: Well, we also had some workshops for the IWB use, performed by third party instructors. But that was more... you know, how to hide the left side of the board, how to move objects from left to right and so on. I think those kind of tricks don't really benefit... well I guess sometimes, to make things more diverse. In primary school even more, I would say. But to have all the lessons prepared in this way... It's good to see what the IWB has to offer, maybe someone will be using it, but I personally couldn't see how this would contribute to a better lesson.

While one may see the established way of using the IWB in physics as underutilization of an expensive piece of technology, the teachers' perspective makes a lot of sense from a pedagogical point of view. If they cannot see how it can significantly benefit physics teaching and learning, they will most likely not invest their time and effort into using it. Paul has even expressed feelings of skepticism towards the level of financial investment required to equip the whole school with IWBs, even though he considers himself to be very interested in the use of modern technology in education.

\section{Students Involved in our Study}

Fifty-four students, 26 in the first, and 28 in the second class, were involved in the study. Two groups of students, one group in each of the two classes where the new lesson was implemented, participated in semi-structured group interviews approximately one week after the lesson's implementation. Each interview group contained students who participated in the lesson in different ways. The first group consisted of two students who actively used the IWB during the lesson (S1G1 and S4G1) and two who did not (S2G1 and S3G1). The second group consisted of three students, of which two used the IWB during the lesson (S2G2 and S3G2) and one did not (S1G2). Although the small groups cannot be considered to be completely representative of the classes they came from, the discussion that unfolded during the interviews pointed to important issues surrounding the new and established ways of using the IWB.

The students' insights into the established culture of IWB use in physics lessons matched those of the teachers - :the IWB was mostly being used as a regular board for writing and drawing. 
Nevertheless, the students expressed appreciation of the "connectedness" of the board- and computer-like use of the IWB, finding it better and "more connected" than the use of an ordinary whiteboard combined with a more traditional computer-projector setup.

As the interviews revealed, IWB use varied strongly between subjects and teachers. ${ }^{2}$ In Anna's physics lessons, students did not use the board very often (one student per lesson, or less), and when they did, they mostly came up to the IWB to solve textbook-style problems, or repeat and write down what they had written in their notebooks in previous lessons. Further discussion with students revealed the importance of the affective component in the their perception of how they used the IWB in physics lessons. When asked about how they felt about coming to the IWB in physics lessons, there seemed to be somewhat of a chasm between the students. Some did not mind it at all (e.g., S1G1) while some found it stressful (e.g., S2G1, $\mathrm{S} 3 \mathrm{G} 1, \mathrm{~S} 4 \mathrm{G} 1$, and S2G2). The main reason for the stress seemed to be the exposure to the risk of public failure. One of the students from Group 2 summed up her feelings of "failing to deliver" in front of the classroom:

S2G2: It is just that you did not know that exact thing at that exact time, so maybe it was something new and you had to take your time to figure it out... So you just stood there and didn't know what to do. That is the worst!

In the interview with Group 1, the students' responses to the question "Are you looking forward of coming to the board?" were:

S2G1, S3G1, S4G1: No.

S1G1: Sometimes.

S2G1: Because you have limited time, you are under pressure... Oh yeah, he (referring to

S1G1) is looking forward to it.

S1G1: Sometimes it's fun.

The students' emotional responses to coming to the front of the classroom appear to be, not surprisingly, related to their confidence in their ability to deliver what is expected of them.

Because the new lesson activities mostly made use of the IWB as a touchscreen device, in contrast to the established use as a writing device, we also probed student's perspectives on the use of touchscreen technology. All interviewed students owned their personal touch screen devices (phone, tablet or e-reader) and felt comfortable and confident using them in their everyday lives. Students from both groups explained that they grew up using these devices and thus felt at ease using them. The following quote from one of the interviews illustrates the prevailing attitude of the students towards new technology, particularly devices.

S2G2: [It] is still easier for us to adapt than for older people. Even if you get a new device, you just grab it and instantly you know how to use it. You will find all the applications, everything. Like my brother and me at home. Whenever there is something new, we are the bosses.

Previous research has suggested that a generation of "digital natives" may have different learning preferences and technological skills than older generations (Prensky 2001). Although this often perceived gap in the ability to use new technologies seemingly correlates with the

\footnotetext{
${ }^{2}$ For example, the students reported that in mathematics, students come to the board to solve problems much more often than in other subjects.
} 
difference in age, research has challenged this claim (Bennett et al. 2008) and suggested that the richness and type of experience when using digital technology can better explain the differences in how well adapted different generations and social groups are for its use (Brown and Czerniewicz 2010). Nevertheless, in the context of our study, students' experiences with using touchscreen technology seem to be an untapped resource for increasing their confidence to actively participate in physics lessons.

\section{Context Summary: the Activities and Tensions Associated with the Established Culture of IWB Use}

Understanding the established culture of IWB use and the relevant tensions that permeate and surround it is crucial, if we wish to better understand the mechanisms that propel the evolution of IWB use. Here, we translate the account given above of the study's context into AT terms and identify tensions that are inherent in the teacher's and students' activities surrounding the use of the IWB that had occurred before our intervention took place. Further analysis follows in sections on the teacher's and students' perceptions, where we look at the impact the intervention itself had on student and teacher activities, how the participants perceived the new way of using the IWB and which new tensions appeared in the process.

\section{The Teacher's and the Students' Activity}

First, we interpret the rich description of the context given above according to Engeström's conceptualization of the activity system. By doing this, we create a schematic representation of how the teacher (Anna) and the students went about the physics lessons, where we pay special attention to how they used the IWB as a tool. Note that such a scheme cannot fully capture the dynamic nature of the activities we describe, but provides merely a momentary snapshot of the activity system, as it evolves.

The first is the teacher's activity (Fig. 2). In it, the subject is the teacher (Anna). The object is instructional goals she sets for her lessons, the tool (on which we focus our attention) is the IWB, and the community consists of several sub-communities that affect her actions-:the

Fig. 2 A schematic representation of the studied activity system from the teacher's point of view. The scheme represents the teacher's object-directed activity

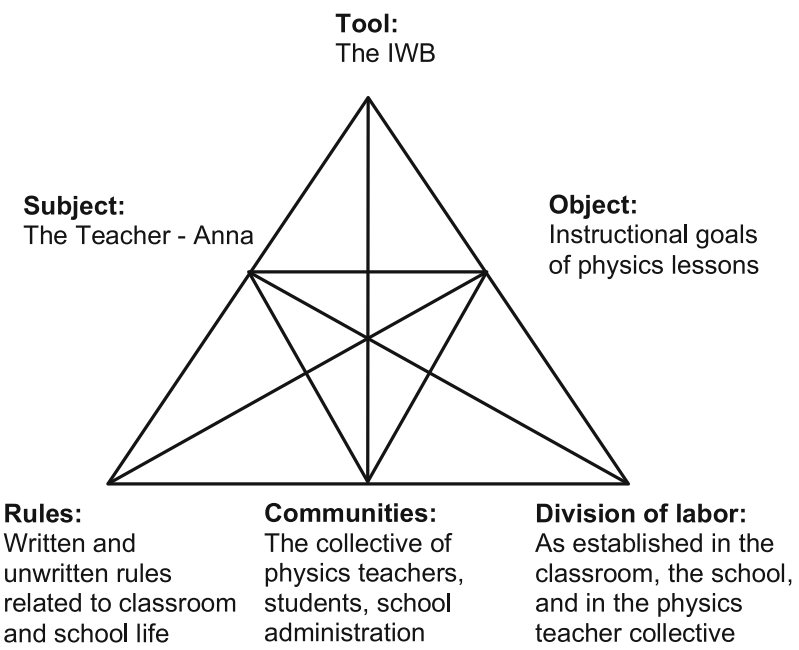


community of students with whom she is working, the community of physics teachers who she interacts with daily and who help her improve her practice, other teachers, the school administration, etc. The implicit and explicit rules and division of labor shape how she participates in these communities, how she goes about her teaching, how she uses the IWB, and what goals she sets for herself and her students.

The other activity of interest is the students' taking part in physics lessons (Fig. 3). In it, the subjects are the students, and the tool on which we focus is the IWB. The object of the student activity is more complex because of the diversity of students we wish to account for. However, for the purpose of this analysis, we choose to focus on those goals that relate to learning physics and/or fulfilling the expectations of the communities in which the students are immersed. These include their peers, the teachers, and their parents. The written and unwritten rules of conduct and the division of labor in the classroom constrain the ways in which students participate in the lessons and use the IWB. From the study of the context, it is clear that the existing division of labor accompanying IWB use has the teacher using it most of the time, and the unwritten rule seems to be that students use the IWB to solve textbook-style problems and not much else.

\section{Crucial Tensions}

We identify crucial tensions, the resolution of which in our case allowed the emergence of a new form of IWB use in the high school physics classroom. To be sure, some tensions were not resolved entirely, other tensions also existed within the studied context, and new tensions emerged throughout the transition towards new ways of using the IWB. By focusing on the selected tensions in the teacher's and the students' activity, we attempt to present the evolution of the classroom activities in a way that balances the points of view of the teacher and the students and provides future researchers, teacher educators, and teachers with potential approaches for resolving similar tensions.

The first tension (Fig. 4), the resolution of which was also the initial goal of our intervention, was the tension within the established way the teacher used the IWB. This was the tension in the upper triangle of the teacher's activity system - between (a) Anna's (subject) objective to improve her lessons (object) and make them more engaging for students with the help of the

Fig. 3 A schematic representation of the studied activity system from the students' point of view. The scheme represents the students' object-directed activity

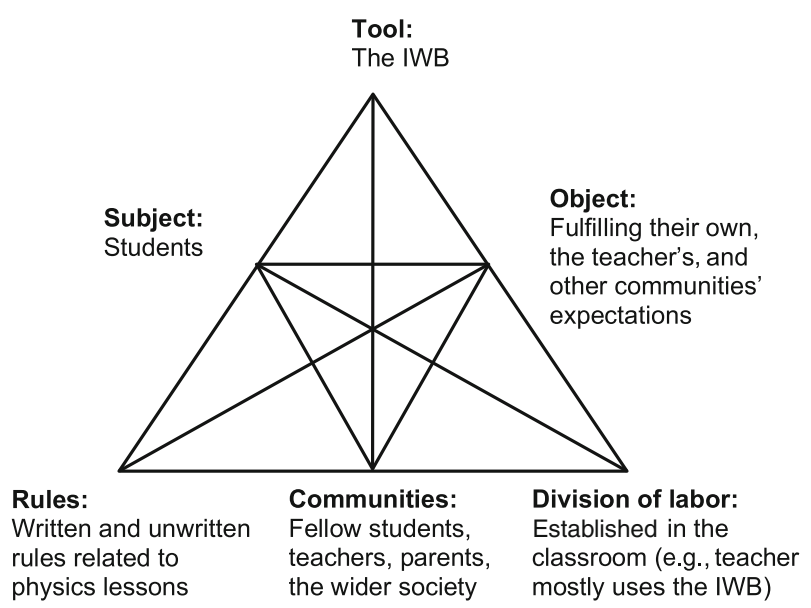

Tool: 
Fig. 4 The figure indicates the tension within the teacher's activity. The tension arises due to the teacher's lack of expertise with the tool in question (the IWB), which she wants to use improve her physics lessons, but does not have concrete ideas how to do it

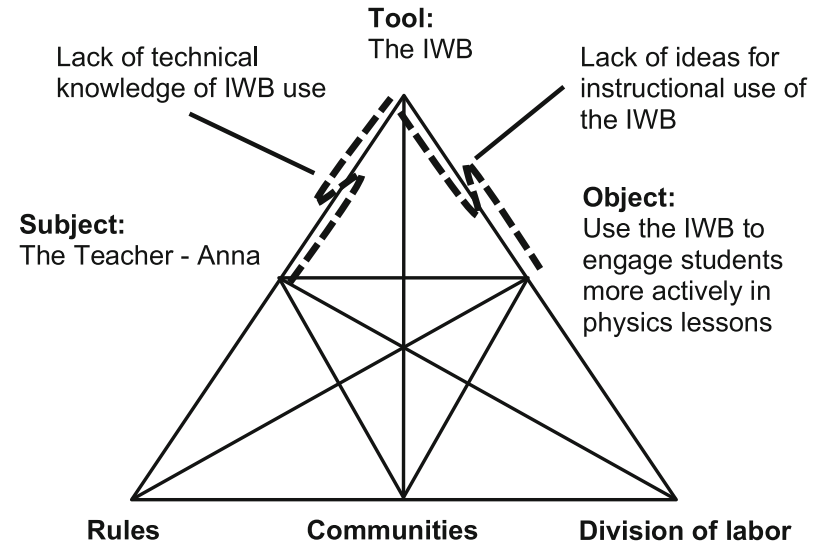

IWB (tool) and (b) her limited knowledge and a lack of ideas for IWB use needed to achieve those goals on her own.

In an attempt to resolve this tension, the researcher presented Anna with prototype materials for a lesson in which the students could learn about Kepler's laws of planetary motion in an engaging way. Anna and the researcher agreed on a way of using the new setup to address the content-related goals of the Kepler's laws lesson. Using the IWB in combination with Algodoo software (www.algodoo.com) allows a kinesthetically engaging activity of "throwing" virtual planets into orbit around a virtual Sun as part of an inquiry-based lesson on Kepler's laws. By the teacher acknowledging the IWB's potential, the tension was partially resolved. It was now clear how the IWB could be used to kinesthetically engage students. However, in order for Anna to be able to productively use the proposed materials in her classroom, she would have to learn how to use the IWB in combination with Algodoo-a piece of software she did not know before.

In the process of teacher preparation and the implementation of the new lesson materials in the classroom, a new tension evolved from the tension discussed above; the tension between the teacher's lack of confidence using the new tools and the pedagogical aim of the lesson- to actively involve students in shaping the course of the lesson (Fig. 5).

Fig. 5 This figure indicates a tension, that emerged during teacher training and the implementation of the lesson. It is related to the tension in Fig. 3 and has arguably evolved from that tension in the process of the transformation of the teacher's activity

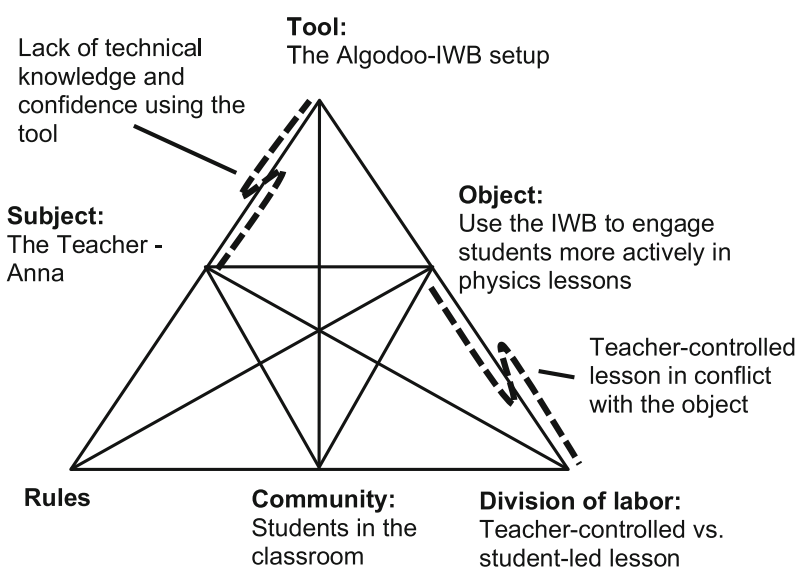


The resolution of this tension would require the teacher to gain significant experience and confidence with the technicalities of the Algodoo-IWB setup, as well as with using it to support students' active inquiry. This tension was only partially resolved during the study.

Another important tension that existed in the students' activity system was the tension between how students use touchscreen technologies in school and out-of-school contexts (Fig. 6). The interviews revealed that while the students saw themselves as competent and confident users of touchscreen devices in out-of-school settings, this did not translate into their willing and confident use of the IWB in the school context, particularly in physics lessons, where the established way of using the IWB was very similar to traditional ways of using a whiteboard (or blackboard) as a writing tool. The resolution of this tension required the new classroom activity to serve as a bridge between using touchscreen technology in playful out-of-school settings and the established high school physics setting. Conveniently, the combination of Algodoo software with the IWB and the topic of Kepler's laws allowed us to do just that. By opening up new possibilities for student engagement, it helped us resolve some of the tension between students' fear of going to the board and their confidence for engaging with digital environments using touchscreen devices.

Introducing a new way of using the IWB thus addressed all of the tensions discussed above (both teacher and student related) simultaneously and gave the established culture of IWB use a nudge in a new direction. While an attempt towards the resolution of tensions in the teacher's activity was the primary aim of our study, the move towards the resolution of the tension in the students' activity came as a welcome side effect. Nevertheless, other studies have shown that engaging students in technology-assisted learning practices that blur the boundaries between physics problem solving and peer cultural practices can help increase students' motivation to take a more active role in high school physics (e.g., Van Dusen and Otero 2015; Van Dusen 2014).

\section{Teacher Training and Lesson Preparation}

We see great value in performing this study in collaboration with a teacher who is not typically involved in "pushing the ICT envelope." It helps us uncover tensions, that may not arise

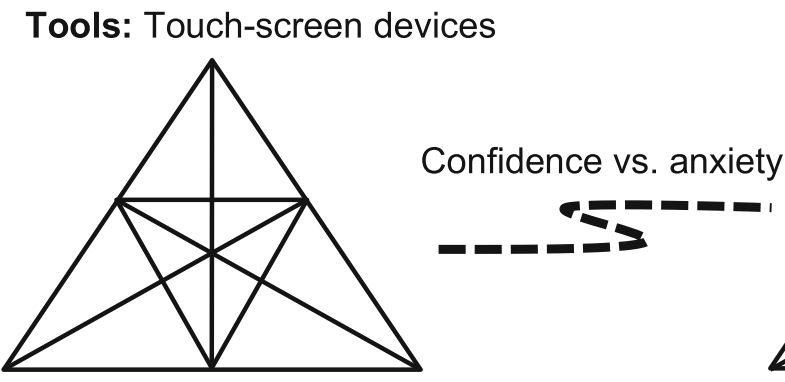

Students' perceptions of the use of touchscreen technology in out-of-school contexts:

- empowering

- ubiquitous

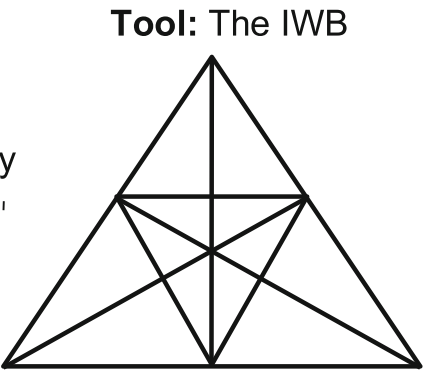

Students' perceptions of the use of the IWB in high school physics lessons:

- often stressful - uncommon

Fig. 6 This figure represents a tension between two bordering student activities linked by the use of touchscreen technology (smart phones and tablets out of school and the IWB in school) 
when working with tech-savvy and tech-enthusiastic teachers but that may be at the center of many teachers' attempts to advance their use of ICT tools in the classroom.

However, recruitment of such teachers for a study similar to ours can be more challenging. We approached this challenge by introducing Anna to IWB-based activities and materials that suited her aim of (helping students learn in engaging ways). This way, we provided her with an opportunity to recognize the potential benefits of the new instructional materials, which led to her deciding to try them out in her own lessons. This line of approach is in-tune with the established mechanisms for the uptake of new technologies in the physics teacher collective at the school. Getting Anna on board was thus made easier by the researcher becoming a part of the physics teacher collective a year prior to the study. First, the researcher designed and implemented the Kepler's laws lesson in his own classroom. Anna got interested in using the materials herself after she heard the researcher and Paul (who was present in the classroom during the researcher's implementation) reflect on the lesson's success.

The researcher worked together with Anna to prepare her for the implementation of the new materials in two of her own classrooms. A detailed analysis of this training and preparation would require a separate paper. We therefore provide a more compressed account of how the teacher and researcher prepared for the implementation of the lesson, with a focus on one particular tension that emerged in the process - : between the learning teacher's confidence (or lack thereof) in using the Algodoo-IWB setup and the intended student-active nature of the lesson.

The two main areas where preparation was necessary were: (a) getting the teacher fluent in the technical operation of the Algodoo software on the IWB and building her confidence in its use and (b) planning the lesson so that the students would actively engage with the IWB.

Anna and the researcher had two training sessions of approximately one hour each. In the first session, the researcher showed Anna some of the capabilities of the Algodoo-IWB setup for lesson activities on the topic of Kepler's laws. Anna then tested the setup's functionality, practiced using the Algodoo-IWB setup, and in the next session asked the researcher some additional questions. Using a one-on-one coaching approach with time to practice between training sessions, we took into account the preferred mode of learning, that anna had expressed in the interview. However, as we will see, the training may have been too short to prepare the teacher for a lesson where student input could be optimally leveraged.

The prototype of the lesson that the researcher presented to Anna in the first training session was primarily designed to take advantage of the IWB as a tool for kinesthetic engagement of students in an inquiry-based lesson. Lesson activities included throwing planets into orbits around the Sun and using different tools within Algodoo software (e.g., the tracer tool and the surface-area measuring tool) to investigate the properties of the planets' orbits (Gregorcic 2015).

In the lesson preparation activity, we identified one particularly interesting tension. The goal - that the lesson should be engaging for students - can come into tension with the teacher's lack of confidence in using the Algodoo-IWB setup (tool). As we further discuss in the following section, Anna was not completely comfortable about letting the students take more control of the course of the lesson because she did not want herself and the students to end-up in "unknown territory." It is very likely that students would come up with ideas that would take the lesson away from its intended course. This concern is especially understandable and realistic in openended inquiry-based learning environments, such as Algodoo, that have ample room for student creativity. Therefore, the teacher's confidence in using Algodool critically influences how the teacher plans and executes the lesson. This tension is illustrated by Anna's statement from an interview that followed Anna watching a video recording of her first implementation of the lesson. 
Anna: I didn't want to wander off somewhere where I wouldn't know... or where it would be hard to get back on track.

\section{Implementation of the New Lesson}

Anna implemented the new instructional materials in two of her classes. Because of spatial limitations, we only provide a description of the first of the two implementations.

The first implementation went according to Anna's plan, but the newly prepared Algodoo-based materials took less time than she had anticipated: only the first 30 minutes of the 45 -minutes lesson. These 30 minutes interest us most.

After the initial few minutes, in which students recited Newton's gravitational law (repetition of the previous lesson) and wrote it down in the form of an equation, Anna introduced the topic of the current lesson to the students. She stated that they would address the motion of objects in the vicinity of a central massive object, which she named the Sun. She then presented Algodoo to the students and made it clear that she was new to the software. She then drew the Sun, commenting on what she was doing as she did it (drawing a circle, setting its mass, etc.). Next, she drew a planet and let it fall to the Sun's surface. A discussion with the students followed. Students suggested that she throw the planet in such a way that it would not fall towards the Sun in a straight line. Some of the students even gestured in the air using their hands to show, what the result of such a throw would be like (circle-like motion). After a failed attempt (throwing too slow), Anna managed to get one planet into an eccentric elliptical orbit.

When she asked if anyone would like to volunteer to come to the IWB, two girls raised their hands. She called one to the board and instructed her step by step on how to create and throw a planet. The first student's throw was too fast, so the planet escaped. However, some students exclaimed: "Wait, wait," and suggested that the planet may return after enough time passed. When the student successfully sent her second planet into a pronounced eccentric orbit, the student selected the zoom tool by herself to zoom out and get the whole orbit onto the screen. Another student (a boy) volunteered and came to the IWB to draw and throw another planet. At this point, many other students started, to suggest how he should draw, grab, and throw the planet. One student suggested that, if possible, the planets should leave traces on the background. The teacher acknowledged this suggestion, but did not attach tracers to planets until later.

At this point, about 15 minutes into the lesson, there was a short break from the Algodoo activity in which Anna, with the help of students, consolidated what they had found so far. She wrote a somewhat augmented version of Kepler's first law (that planets' orbits have elliptical shapes, not mentioning where the foci of the ellipses are) on the board and the students copied it into their notebooks.

In the second 15-minutes segment of the lesson, the IWB was used only by Anna. She attached a tracer of short duration to one of the planets and drew two separate shapes corresponded to shapes, which an imaginary line connecting the planet and the sun sweeps out in a given time interval (determined by the tracer duration). The students noticed and pointed out that the angles that the planet had traveled in the two equally long time intervals were different. When Anna asked them if anything was the same, the students suggested (hypothesized) that the drawn shapes' surface area was equal. Anna, pleased with their response, then used a surface area-measuring tool to compare the surface area of the two shapes and concluded together with students that 
they are almost identical (taking into account some error when drawing the shapes by hand). She then wrote down Kepler's second law on the board (that an imaginary line connecting the planet and the Sun always sweeps out equal surface areas in a given time interval). Although the students seemed fairly engaged and participated by stating out loud their observations, they did not get to use the IWB any more in the lesson.

The lesson continued with Anna creating and sending two planets into perfectly circular orbit using the built-in "send into orbit" tool. She asked the students to observe and look for patterns in the simulation. They noticed that the planet father away was moving slower. Anna restated this student observation, rephrased it in terms of orbital period (longer periods for planets orbiting father away), and added that this pattern (Kepler's third law) can also be expressed quantitatively.

The last 15 minutes of the lesson were very similar to Anna's usual lessons on this topic. Anna used the writing software to derive Kepler's third law from Newton's second law for circular motion and Newton's gravitational law. She did this with some student cooperation (she asked students to provide the requisite equations). She drew the free body diagram, wrote down Newton's second law, and asked students to provide an equation connecting the radial acceleration and the velocity of an object. She added the derived equation to the list of laws and made the final consolidation of the findings. Finally, she also added to the first law that the Sun is located in one of the ellipse's foci and asked students if anyone knew these three statements from what had been discussed previously. One student recognized them as Kepler's laws. The teacher then continued with lecturing briefly about the historical context of the discovery of Kepler's laws.

The lesson concluded with Anna using a separate simulation, which showed a projectile being repeatedly fired parallel to the Earth's surface with increasing speed, until it starts to orbit it.

\section{Teacher Perspective: Resolving a Tension in the Teacher's Activity}

While the teacher's and researcher's overall impression of the lesson was positive, both agreed that there was room for improvement.particularly in terms of student contributions. Anna admitted, after watching the video recording of the lesson that she should have engaged the students more. The teacher was experiencing a tension between one of the intended goals of the implementation - student active engagement - and her skills and confidence with the new tool- the Algodoo-IWB setup.

As we have already pointed out, Anna felt uncomfortable letting students do things, that could "lead the lesson astray." This was one way in which Anna's lack of confidence restrained the possibilities for student engagement. There was, however, another way in which the teacher's lack of confidence had an impact on the way she chose to facilitate student engagement. Not being particularly confident in the use of the Algodoo-IWB setup herself, she was less want decisive about calling students to the board. This issue is clearly illustrated by the following excerpt from a follow-up interview with Anna, after the lesson implementation, the researcher's interview with the students, and repeated viewings of the lesson video recording:

Researcher: [F]or example one student said: "I would like to do that too!" when the first planet was being thrown into orbit.

Anna: So why didn't he come to the board?

Researcher: Well, that is the thing, they didn't quite have the courage. Maybe a more relaxed approach would do the trick. 
Anna: Yes, I would do that if I were more confident, for sure. But as it was, I didn't want to force them.

In the excerpt, we can see the links between tensions in both the teacher's and students' activities. The researcher, having talked to the students, knew that the students were cautious and shy because they did not know what was expected of them and were initially afraid of exposing themselves.

In the second implementation of the lesson in another class (which we do not describe in detail because of spatial limitations), Anna gave students more opportunities for explorative engagement on the IWB. The lesson thus turned out to be more engaging for the students, but at the same time stalled quite a few times due to technical issues, where the teacher's lack of in-depth understanding of the setup's features and limitations became a hindering factor for the lesson's flow. This further supports our finding that there was a crucial tension between a teacher's lack of in-depth knowledge of the Algodoo-IWB setup (the tool of interest) and the pedagogical aims of the lesson - active student engagement in inquiry-based activities.

How can this tension be resolved? One possibility, which Anna chose in the first implementation, is to retain more direct control over the lesson's progression and limit possible excursions into "unknown territory." One example of such rigid planning from the lesson described above is where Anna did not add a tracer to the planet, when the student suggested it because it did not match her lesson plan. Later, after watching the lesson recording, both the researcher and the teacher agreed that this was a missed opportunity for providing students with more agency and letting them take some of the control of the course of the lesson. In the second implementation, Anna gave students more freedom to try things out themselves. However, not having enough experience with the software and its limitations led to situations when neither the teacher nor the students knew why the software was behaving the way it was, which stalled the lesson. This issue was also brought up by the students in the interview, when the researcher asked them if there was something in the lesson that could be improved:

S1G2: Well, the teacher at least should be more familiar with the software so we could advance faster, there wouldn't be so many problems and things wouldn't have to be repeated... um. Only this, I would say.

S2G2: I agree. This always influences things. If the teacher is uncertain, you can see that.

So you could see that we did less than the teacher planned.

S3G2: I agree.

It seems that given her degree of familiarity with the Algodoo-IWB setup, Anna had to choose between a rigidly planned lesson and a lesson where too much time was spent unproductively managing the software in new and unknown situations. While both options are far from optimal, we believe most teachers would consider the second option even less favorable than the first one.

The more productive possibility is, obviously, that teachers gain sufficient knowledge and confidence in using the technological setup. This way, teachers know the limitations and affordances of the setup and are able to predict in advance the possible productive and unproductive outcomes of student ideas and adjust their guidance accordingly. However, technical proficiency is not sufficient for a lesson to be pedagogically interactive and meaningfully engaging for the students. The teacher's commitment towards pursuing an active learning environment provided he or she has the requisite knowledge and skills to support it is at the core of this issue. If the teacher does 
not see value in actively engaging students in IWB-based inquiry, no amount of proficiency with the tool will help. In this case, we would not expect any spontaneous emergence of the tension discussed above at all.

Taking a step back and looking at teacher's learning activity (learning to use the new setup), the requirement that the teacher be confident with the use of the tools (the preferred goal of the learning activity) may be in further tension with the teacher's available time and/or the teacher's motivation to spend time experimenting with the tools, in order to develop a deep understanding of their possibilities. Many factors, such as the support of the communities in which a teacher works and develops, influence how this tension may be resolved. Taking part in a supportive community of practitioners who engender technology-related expertise and frequently exchange ideas and strive towards constant professional growth appears to be a healthy environment for advancing a teacher's technology skills.

\section{The Learners' Perspective: Resolving a Tension in the Learners' Activity}

Assuming that any teaching should have the student as its primary focus, it is crucial that we consider how students perceived and responded to what was happening in the classroom during the implementation of the new lesson materials. By interviewing the students, we found that the new materials disrupted the established culture of IWB use. We identified and focused on one tension that existed in the established way of IWB use prior to our intervention and examined whether this tension was to any degree resolved by the new way in which the IWB was used in the implementation.

The critical tension that we have identified in the students' activity in the classroom is that between the differing levels of confidence in using modern technology in and outside of school. This tension was present in the established activities surrounding the use of the IWB in physics lessons, as well as in the newly implemented lessons. However, there is some indication that important steps towards resolving this tension were made in our implementation. As we have found, the way students perceive and frame the nature of the classroom activity has an impact on their willingness to engage with the IWB in front of the classroom.

The following excerpts from the interviews reveal how the students who volunteered to come to the board were thinking:

Researcher: And you (S4G1) volunteered too.

S4G1: Yes, I did, because I found it interesting, and me not being a very physics kind of person, I thought that maybe by trying myself, I could imagine better. But it was true that the first one [planet] flew away; I threw it too hard.

Two mechanisms can be seen to have contributed to the tension's resolution. The first is igniting the students' interest by providing them with appealing opportunities for engagement. However, this is arguably not enough, if the students are afraid of failing. Thus, in a context similar to ours, a student anxiety reduction mechanism also needs to be in place. Framing these activities as playful exploration may alleviate the students' stress and allow them to engage in the lesson with less fear. Anna succeeded in establishing an atmosphere where students were prepared to engage by framing the new activities as play at the beginning of the lesson. In the second interview, the researcher talked to a student who volunteered to come to the IWB:

Researcher: So did the fact that you knew what you will be doing influence your decision? So you knew it is not going to be task solving, but something else. 
S2G2: Yes, I saw that it is nothing that I could do wrong and that it was fun, at least for me.

What we find most interesting with students S4G1 and S2G2 is that they both declared themselves not being particularly engaged in physics and typically not feeling comfortable in coming to the front of the classroom in physics lessons. This indicates that a departure from the established dynamics of a physics lesson and culture of IWB use had taken place. What is most encouraging is that the new lesson activities effectively opened up the engagement space for students who do not consider themselves "a physics kind of person." This may be one of the most valuable transformations accompanying the new way of using the IWB in the physics classroom.

What further sparked our interest was the ease and confidence with which these students used the Algodoo-IWB setup, despite using it for the first time. Anna also noticed this, when one of the students using the IWB spontaneously used the zoom tool to look for a planet that "escaped" out of the field of vision, as she noted in the follow-up interview:

Anna: [I] think she used the zoom tool by herself, because I was somewhat surprised to see that. Like she knew the software.

Students thus appeared to be well equipped to use the IWB in a way that resembled their dayto-day use of touchscreen devices and quickly picked up its basic functions by simply observing the teacher working with it. Leveraging the students' confidence in using such technology is thus a potential way of resolving the tension between the students' confidence with out-ofschool use of touchscreen technology and students' anxiety accompanying the established way of using of the IWB in physics lessons.

\section{Discussion and Implications}

Our case study of the implementation of new physics instructional materials, that use the IWB's affordances for student active engagement, has revealed interesting tensions accompanying both the established ways of using the IWB in physics lessons, and those accompanying the newly implemented lesson materials. In addition to identifying these tensions, we have also proposed mechanisms for their resolution.

The first tension we have identified in the established practice of teaching physics with the use of the IWB was that of the teacher wishing to use the IWB in more effective ways, which included a more active approach to student participation in the lessons, but not seeing appropriate opportunities or ways to do so. Our suggestion to the teacher of new ways of using the IWB was an attempt at resolving this tension. We suggest that high school physics teachers use of the IWB in ways that go beyond what an ordinary whiteboard and a projector setup can do, this requires a focused effort on the development of instructional materials that will be able to convince the high school physics teacher by offering a sufficient level of physics sophistication, and pedagogical appeal. We found the Algodoo-IWB setup to be a good candidate for doing just that.

Algodoo-IWB setup to be a good candidate for doing just that. planning and implementation of the new materials in the classroom and was related to the one just discussed, as it concerns the relationship between the teacher's goals and her mastery of the tools - : the Algodoo-IWB setup. Namely, the aim of actively engaging students and giving them control of the course of 
the lesson was in apparent opposition to teacher's need to have the lesson carefully prepared in order to stay out of "unknown territory" of IWB use. This is perhaps one of the most natural dilemmas teachers face.

Moreover, this tension may be a manifestation of another tension, that is particularly pertinent in physics. The epistemological commitments of physics give experiments a central role. For example, observational experiments, where physicists observe unknown phenomena and describe what happens, or testing experiments, where they predict the outcomes of the experiments based on different hypotheses in order to be able to falsify them, are part of physicists' everyday work (Etkina 2015). However, in physics, instruction experiments are most often used to demonstrate the point that teacher or a textbook made already (that is why they are called demos). If physics instruction's aim is to teach students about physics practices, it is particularly important that students encounter experiments in ways that differ from the traditional "demonstrations." The idea of demonstrations - teacher directed and performed experiments - permeates the culture of physics teaching (Meiners 1970; Taylor 1988). Therefore, having a traditional teacher shift the agency in using the IWB (which is in our case used more as an experiment than a writing tool) to the students requires them to simultaneously change the way they use experiments in the classroom; from teacher demonstration to student participation.

Well-controlled experiments (such as demonstrations), which allow teacher to present content in a "clean" and predictable way, are in tension with the goals, which emphasize the development of students scientific competences. In the case of the Algodoo-IWB setup, no degree of teacher proficiency with the tool is sufficient for making the lesson engaging for the students, if the teacher is not prepared and willing to let students take some control of the IWB, and with it, the lesson.

However, a teacher who is genuinely committed to shifting the agency to the students, must have the confidence to master the technology he or she is using. This once again brings us to the tension that we observed in our study. Mastery of the tool means that the teacher has a good overview of the possibilities and limitations of the technological setup, knows how to use it and how to help students use it, and is able to confidently decide on-the-fly, in the unpredictable circumstances of authentic classrooms, when to allow students to wander about, and when to more firmly direct and scaffold their inquiry. When using the IWB with Algodoo software, the tension between the need for giving more control to students and the "fear of letting go" can therefore be resolved by building teacher's confidence in using the Algodoo-IWB setup so that opportunities for giving more control to students and, possible dead-ends can be anticipated. One way of achieving this is to provide the teacher with enough time to experiment with the Algodoo-IWB setup. However, if this requires spending long hours practicing in addition to the normal workload, we can expect only the most enthusiastic teachers to do so. On the other hand, an approach, where the teacher learns to use just a narrow set of features, most likely means sticking rigidly to the lesson plan and possibly forgoing or missing opportunities to shift agency towards students.

The last tension we discuss is the tension accompanying the established culture of IWB use, namely the students' attitude towards using technology similar to the IWB in out-of-school contexts, and using the IWB in physics lessons. While we recognize this tension as being inherent in the existing culture of IWB use, it also played an important role in shaping the dynamics of the lessons where the IWB was being used in a new way. 
The interviews revealed that the culture of using the IWB in physics is practically the same as using a traditional board, despite its versatile pedagogical affordances. The students also expressed their reluctance to participate in physics lessons that require coming to the front of the classroom to do traditional problem solving on the board. They see coming to the IWB as exposing themselves to possible failure. A very encouraging finding of the study was that by introducing a new way of using the IWB and reframing what happens in front of the class as playful exploration in a computer-based environment, we can stimulate students who otherwise rarely consider actively participating in physics lessons to volunteer and come to the IWB to perform tasks. A possible explanation forthese occurrences is that by altering the function of the IWB and using it as a touchscreen device, instead of a writing tool, we have leveraged the confidence and experience students have in using such technology, that they have gained in out-of-school situations. This way of leveraging the IWB can resolve the tension in the students' perceptions of technology use in and outside of the classroom and may for some students open up new approach pathways to engaging in physics lessons. The most intriguing finding was that the new materials have the potential to engage "not the physics kind of students" (as one of the students identified herself) in investigative activities in large classroom settings. These students attributed their decision to actively engage to the nature of the IWB activity, which reduced their anxiety to perform in front of the classroom.

In conclusion, we managed to prepare (though not optimally) a teacher to change her usual lesson on Kepler's laws and introduce student-centered IWB-based kinesthetic activities by leveraging the way in which innovation is typically spread within the physics-teacher community at the school. By doing this, we managed to establish, at least temporarily, a new approach to using the IWB in the physics classroom. The collected interview data, particularly from students, revealed that there may be significant potential in the new way of using the IWB - as a tool for engaging students in playful and kinesthetically engaging inquiry - to open up new avenues of participation for students who otherwise do not perceive themselves to be " physics kind of people."

Preparing the teacher for the implementation of the new materials required the researcher to become a trusted member of the physics-teacher community. We suggest that more time and resources be delegated to facilitating professional development of teachers, that instead of taking teachers out of the contexts of their subject's professional communities, builds on the existing social infrastructure of subject-teachercollectives (for example, the physics-teacher collective at the school, in our study), leverages established communication channels to introduce new ideas about how technology can improve learning, and encourages implementation of the new ideas in the classroom. At the same time, there remains great need for lesson materials, that contribute to the learning of physics at the high school level, take advantage of the IWB's technical possibilities, and leverage them for the active engagement of students.

Open Access This article is distributed under the terms of the Creative Commons Attribution 4.0 International License (http://creativecommons.org/licenses/by/4.0/), which permits unrestricted use, distribution, and reproduction in any medium, provided you give appropriate credit to the original author(s) and the source, provide a link to the Creative Commons license, and indicate if changes were made. 


\section{References}

Barab, S. A., Barnett, M., Yamagata-Lynch, L., Squire, K., \& Keating, T. (2002). Using activity theory to understand the systemic tensions characterizing a technology-rich introductory astronomy course. Mind, Culture, and Activity, 9(2), 76-107. doi:10.1207/S15327884MCA0902 02.

Barab, S. A., Evans, M. A., \& Baek, E. O. (2004). Activity theory as a lens for characterizing the participatory unit. In Jonassen, D. H. (Ed.), Handbook of Research on Educational Communications and Technology (2nd ed.) (pp. 199-214). Mahwah: Lawrence Erlbaum Associates Publishers.

Bax, S. (2010). Magic wand or museum piece? The future of the interactive whiteboard in education. In M. Thomas \& E. Cutrim Schmid (Eds.), Interactive whiteboards for education: theory, research and practice (pp. 264-277). Hershey: IGI Global. doi:10.4018/978-1-61520-715-2.

Beach, J. (2012). Interactive whiteboard transition: a case study. Doctoral dissertation: University of Tennessee Retrieved from http://trace.tennessee.edu/utk graddiss/1266/.

Bennett, S., Maton, K., \& Kervin, L. (2008). The "digital natives" debate: a critical review of the evidence. British Journal of Educational Technology, 39(5), 775-786. doi:10.1111/j.14678535.2007.00793.x.

Blanton, P. (2008). Using interactive whiteboard to enhance student learning. The Physics Teacher, 46(3), 188. doi:10.1119/1.2840991.

Brown, C., \& Czerniewicz, L. (2010). Debunking the "digital native": beyond digital apartheid, towards digital democracy. Journal of Computer Assisted Learning, 26(5), 357-369. doi:10.1111 /j.1365-2729.2010.00369.x.

Cole, M., \& Engeström, Y. (1993). A cultural-historical approach to distributed cognition. In G. Salomon (Ed.), Distributed cognitions: psychological and educational considerations (pp. 1-46). Cambridge: Cambridge University Press.

Condie, R., \& Munro, B. (2007). The impact of ICT in schools - a landscape review. Retrieved from http://www. ibertic.org/evaluacion/sites/default/files/biblioteca/33_impact_ict_in_schools.pdf.

Creswell, J. W. (2013). Qualitative inquiry and research design: choosing among five approaches. Thousand Oaks: SAGE Publications.

Cutrim Schmid, E. (2011). Video-stimulated reflection as a professional development tool in interactive whiteboard research. ReCALL, 23(3), 252-270. doi:10.1017/S0958344011000176.

Education Reform Initiative (ERI). (2013). Turkey's FATIH project: a plan to conquer the digital divide or a technological leap of faith? Retrieved from http://www.egitimreformugirisimi.org/sites/www. egitimreformugirisimi.org/files/Fatih.rapor_.ENG_.son_.pdf.

Engeström, Y. (1987). Learning by expanding. Helsinki: Orienta-Konsultit Oy.

Engeström, Y. (2000). Activity theory as a framework for analyzing and redesigning work. Ergonomics, 43(7), 960-974. doi:10.1080/001401300409143.

Engeström, Y. (2011). From design experiments to formative interventions. Theory \& Psychology, 21(5), 598628. doi:10.1177/0959354311419252.

Etkina, E. (2015). Millikan award lecture: students of physics - Listeners, observers, or collaborative participants in physics scientific practices? American Journal of Physics, 83(8), 669-679. doi.10.1119/1.4923432.

Gregorcic, B. (2015). Exploring Kepler's laws using an interactive whiteboard and Algodoo. Physics Education, 50(5), 511-515. doi:10.1088/0031-9120/50/5/511.

Gregorcic, B., Etkina, E., \& Planinsic, G. (2014). Effective use of interactive whiteboards: a design based research approach. In L. Dvořák \& V. Koudelková (Eds.), ICPE-EPEC 2013 Conference Proceedings (pp. 432-438). Prague: Matfyzpress publishing. Retrieved from http://www.icpe2013.org/uploads/ICPEEPEC_2013_ConferenceProceedings.pdf.

Gray, C. (2010). Meeting teachers' real needs: new tools in the secondary modern foreign languages classroom. In M. Thomas \& E. Cutrim Schmid (Eds.), Interactive whiteboards for education: theory, research and practice (pp. 69-85). Hershey: IGI Global. doi:10.4018/978-1-61520-715-2.ch005.

Hennessy, S., \& London, L. (2013). Learning from International Experiences with Interactive Whiteboards: The Role of Professional Development in Integrating the Technology. OECD Education Working Paper No. 89. Retrieved from http://ideas.repec.org/p/oec/eduaab/89-en.html.

Hennessy, S., Deaney, R., Ruthven, K., \& Winterbottom, M. (2007). Pedagogical strategies for using the interactive whiteboard to foster learner participation in school science. Learning, Media and Technology, 32(3), 283-301. doi:10.1080/17439880701511131.

Higgins, S., Beauchamp, G., \& Miller, D. (2007). Reviewing the literature on interactive whiteboards. Learning, Media and Technology, 32(3), 213-225. doi:10.1080/17439880701511040.

Jonassen, D. H., \& Rohrer-Murphy, L. (1999). Activity theory as a framework for designing constructivist learning environments. Educational Technology Research and Development, 47(1), 61-79. doi:10.1007 /BF02299477. 
Kaptelinin, V., \& Nardi, B. (2006). Acting with technology: activity theory and interaction design. Cambridge: MIT Press.

Kennewell, S. (2006). Reflections on the interactive whiteboard phenomenon: a synthesis of research from the UK. In Proceedings of the Annual Conference of the Australian Association for Research in Education. Adelaide. Retrieved from http://www.ore.org.pt/filesobservatorio/pdf/KENNEWELL.pdf

Kennewell, S., \& Morgan, A. (2003). Student teachers' experiences and attitudes towards using interactive whiteboards in the teaching and learning of young children. In Proceedings of the IFIP Working Groups 3.5 Conference: Young Children and Learning Technologies (pp. 65-69). Parramatta. Retrieved from http://dl. acm.org/citation.cfm?id=1082070.

Kennewell, S., Tanner, H., Jones, S., \& Beauchamp, G. (2007). Analysing the use of interactive technology to implement interactive teaching. Journal of Computer Assisted Learning, 24(1), 61-73. doi:10.1111/j.13652729.2007.00244.x.

Kershner, R., Mercer, N., Warwick, P., \& Kleine Staarman, J. (2010). Can the interactive whiteboard support young children's collaborative communication and thinking in classroom science activities? International Journal of Computer-Supported Collaborative Learning, 5(4), 359-383. doi:10.1007/s11412-010-9096-2.

Koenraad, A. (2008). Interactive whiteboards in educational practice: the research literature reviewed. Retrieved from http://documents.mx/documents/interactive-white-boards-in-educational-practice.html.

Leontiev, A. N. (1978). Activity, consciousness, and personality. Englewood Cliffs, NJ, USA: Prentice-Hall.

Meiners, H. F. (1970). Physics demonstration experiments (1st ed.). Malabar: Krieger Pub. Co.

Mellingsæter, M. S., \& Bungum, B. (2015). Students' use of the interactive whiteboard during physics group work. European Journal of Engineering Education, 40(2), 115-127. doi:10.1080 /03043797.2014.928669.

Mercer, N., Hennessy, S., \& Warwick, P. (2010). Using interactive whiteboards to orchestrate classroom dialogue. Technology, Pedagogy and Education, 19(2), 195-209. doi:10.1080/1475939X.2010.491230.

Moss, G., Jewitt, C., Levacic, R., Armstrong, V., Cardini, A., \& Castle, F. (2007). The Interactive Whiteboards, Pedagogy and Pupil Performance Evaluation: An Evaluation of the Schools Whiteboard Expansion (SWE) Project: London Challenge. Institute of Education, Research report No. 816. Retrieved from http://eprints. ioe.ac.uk/905/1/Moss2007whiteboardsRR816.pdf.

Murcia, K. (2014). Interactive and multimodal pedagogy: a case study of how teachers and students use interactive whiteboard technology in primary science. Australian Journal of Education, 58(1), 74-88. doi: $10.1177 / 0004944113517834$.

Murcia, K., \& Sheffield, R. (2010). Talking about science in interactive whiteboard classrooms. Australasian Journal of Educational Technology, 26(4), 417-431. doi:10.14742/ajet.1062.

Ormanci, U., Cepni, S., Deveci, I., \& Aydin, O. (2015). A thematic review of interactive whiteboard use in science education: rationales, purposes, methods and general knowledge. Journal of Science Education and Technology. doi:10.1007/s10956-014-9543-3.

Prensky, M. (2001). Digital natives, digital immigrants. On the Horizon, 9(5), 1-6. doi:10.1108 $/ 10748120110424816$.

Slay, H., Siebörger, I., \& Hodgkinson-Williams, C. (2008). Interactive whiteboards: real beauty or just "lipstick"? Computers \& Education, 51(3), 1321-1341. doi:10.1016/j.compedu.2007.12.006.

Smith, H. J., Higgins, S., Wall, K., \& Miller, J. (2005). Interactive whiteboards: boon or bandwagon? A critical review of the literature. Journal of Computer Assisted Learning, 21(2), 91-101. doi:10.1111/j.1365-2729.2005.00117.x.

Somekh, B., Haldane, M., Jones, K., Lewin, C., Steadman, S., Scrimshaw, P., ... Woodrow, D. (2007). Evaluation of the primary schools whiteboard expansion project - summary report. Report to the Department for Children, Schools and Families. Retrieved from http://archive.teachfind.com/becta/research.becta.org.uk/uploaddir/downloads/page_documents/research/whiteboards_expansion.pdf.

Somyürek, S., Atasoy, B., \& Özdemir, S. (2009). Board's IQ: what makes a board smart? Computers \& Education, 53(2), 368-374. doi:10.1016/j.compedu.2009.02.012.

Stoica, D., Paragina, F., Paragina, S., Miron, C., \& Jipa, A. (2011). The interactive whiteboard and the instructional design in teaching physics. Procedia - Social and Behavioral Sciences, 15, 3316-3321. doi:10.1016/j.sbspro.2011.04.292.

Sweeney, T. (2013). Understanding the use of interactive whiteboards in primary science. Australasian Journal of Educational Technology, 29(2), 217-232. doi:10.14742/ajet.26.

Taylor, C. (1988). The art and science of lecture demonstration. New York: Taylor \& Francis.

Van Dusen, B. (2014). The roots of physics students' motivations: fear and integrity. Doctoral dissertation: University of Colorado Boulder.

Van Dusen, B., \& Otero, V. K. (2015). From fear to self-expression: the contextual nature of physics students' motivations. In 2014 physics education research conference proceedings (pp. 255-258). Minneapolis: American Association of Physics Teachers. doi:10.1119/perc.2014.pr.060. 
Van Veen, N. (2012). Interactive White Board in Physics Teaching; beneficial for physics achievement? Master's dissertation Universiteit van Amsterdam .Retrieved from http://www.science.uva. nl/onderwijs/thesis/centraal/files/f1045808677.pdf

Vercellati, S., \& Michelini, M. (2014). The IWB as a bridge between phenomena exploration and interpretation of electromagnetic phenomena in construction of formal thinking. In S. Dormido \& L. de la Torre (Eds.), MPTL18 - Book of Proceedings (pp. 107-112). Madrid: European Physical Society.

Vygotsky, L. (1978). In M. Cole, V. John-Steiner, S. Scribner, \& E. Souberman (Eds.), Mind in society: the development of higher psychological processes. Cambridge: Harvard University Press.

Warwick, P., \& Kershner, R. (2008). Primary teachers' understanding of the interactive whiteboard as a tool for children's collaborative learning and knowledge-building. Learning, Media and Technology, 33(4), 269287. doi:10.1080/17439880802496935.

Winzenried, A., Dalgarno, B., \& Tinkler, J. (2010). The interactive whiteboard: a transitional technology supporting diverse teaching practices. Australasian Journal of Educational Technology, 26(4), 534-552. 